\title{
Cisplatin/Paclitaxel/Cetuximab Regimen
}

National Cancer Institute

\section{Source}

National Cancer Institute. Cisplatin/Paclitaxel/Cetuximab Regimen. NCI Thesaurus. Code C150693.

A chemoimmunotherapy regimen consisting of cisplatin, paclitaxel and cetuximab that can be used for the treatment of head and neck cancer. 